\title{
Improvement of the Initial Stage of Solidification by Using Mild Cooling Mold Powder*
}

\author{
Masayuki KAWAMOTO, Yuichi TSUKAGUCHI,") Norihiro NISHIDA, Takashi KANAZAWA and \\ Sei HIRAKI
}

Corporate Research and Development Laboratories, Sumitomo Metal Industries, Ltd., Sunayama, Hasaki, Kashima-gun, Ibaraki-ken, 314-02 Japan. Wakayama-ken, 640 Japan.

(Received on June 19, 1996; accepted in final form on September 9, 1996)

\begin{abstract}
The initial stage of solidification for continuous casting is very important in optimising the surface quality of steel. It is well known that hypo-peritectic steel has problems with longitudinal cracking due to shrinkage resulting from the $\delta \rightarrow \gamma$ transformation. High speed continuous casting, with a speed range of $4-5 \mathrm{~m} / \mathrm{min}$, suffers from the same problem. For a round-shaped billet caster, the shape of the mold cross section is at a disadvantage with regard to longitudinal cracking. In this study, mild cooling mold powders were developed in order to improve the surface quality of high speed casting slabs and round-billets. The results can be summarized as follows; 1) High $\mathrm{CaO} / \mathrm{SiO}_{2}$ ratio mold powder with a high solidification temperature is most suitable for a slab caster. 2) Low $\mathrm{CaO} / \mathrm{SiO}_{2}$ ratio mold powder with a high solidification temperature is most suitable for a round billet caster. 3) The effect of radiation in liquid powder film is bigger than solid powder film.
\end{abstract}

KEY WORDS: hypo-peritectic steel; continuous casting; high speed casting; mold powder; round billet CC; slab CC; longitudinal cracking.

\section{Introduction}

The initial stage of solidification in continuous casting is very important with regard to the surface quality of the steel. It is well known that hypo-peritectic steel has problems with longitudinal cracking due to shrinkage associated with $\delta \rightarrow \gamma$ transformation. ${ }^{1)}$ High speed continuous casting, with a speed range of $4-5 \mathrm{~m} / \mathrm{min}$, suffer from the same problem. ${ }^{2)}$ For a round-shaped billet caster, the shape of the mold cross section is at a disadvantage with regard to longitudinal cracking. ${ }^{3)}$ It is also known that such uneven solidification at initial stage is improved by the use of mild cooling. ${ }^{4)}$ Many studies to improve mold and mold powder have been carried out. ${ }^{5-7)}$ In this study, mild cooling mold powders were developed in order to improve of the surface quality of high speed casting slab and round-billet.

\section{Mild Cooling Mold Powder for Slab CC}

For a high speed caster, with a speed range of $4-5 \mathrm{~m} /$ min, the main problem is longitudinal cracking for all grades of steel. High $\mathrm{CaO} / \mathrm{SiO}_{2}$ ratio mold powder with a high solidification temperature can be applied. ${ }^{8)}$ Figure 1 shows the relation between heat flux in the mold and the incidence rate of longitudinal cracking when casting at a speed range of $4-5 \mathrm{~m} / \mathrm{min}^{2)}$

\subsection{Cause of Longitudinal Cracking in Steel Surface}

For a high speed caster, with a speed range of 4-5 m/ min, longitudinal cracking of low carbon aluminiumkilled steel $(0.05$ mass $\%$ C $)$ occurred. It can be seen

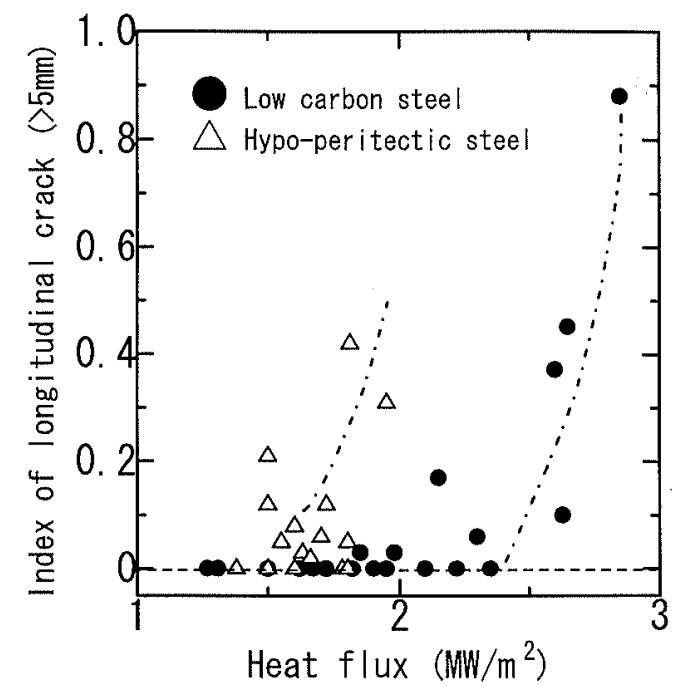

Fig. 1. Relation between index of longitudinal cracking and heat flux. ${ }^{21}$

$(100 \times 1000$ mold, casting speed $2-5 \mathrm{~m} / \mathrm{min})$

\footnotetext{
* This paper was presented in the "International Workshop on Thermophysical Data for the Development of Mathematical Models of Solidification" held at Gifu City from 6-8 October, 1995.
} 


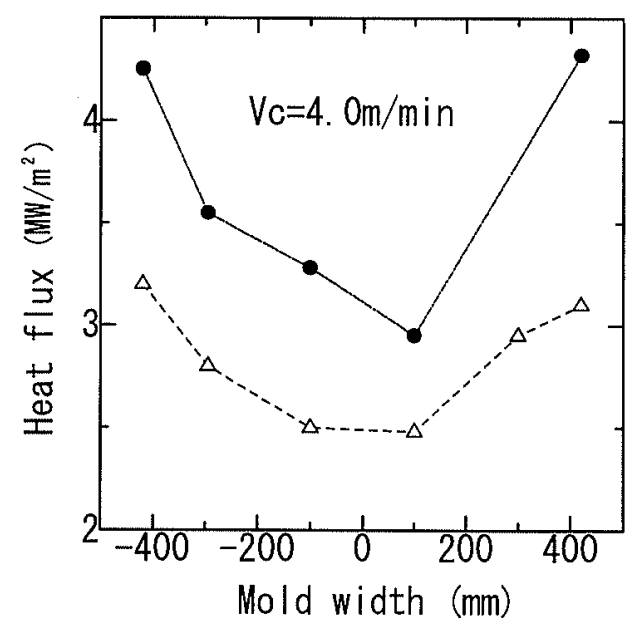

Fig. 2. Distributions of heat flux of mold wide face. ${ }^{2)}$

- $\mathrm{CaO} / \mathrm{SiO}_{2}: 0.95$ solidification temp. $1252 \mathrm{~K}$ $\triangle: \mathrm{CaO} / \mathrm{SiO}_{2}: 1.20$ solidification temp. $1233 \mathrm{~K}$ (longitudinal cracking $\rightarrow 0: 0.081, \triangle: 0(\mathrm{~m} / \mathrm{m})$ ) Longitudinal cracking index means cracking length per slab length.

from Fig. 1, longitudinal cracking occurred only when absolute values of heat flux exceeded certain critical values. However, these critical values are different for different steel grades.

Heat flux distribution horizontally across the wide face, for a speed range of 4-5 m/min, is shown in Fig. 2 . The heat flux in the center is low and the heat flux along the sides is high. It is known that this phenomenon is associated with the flow pattern of molten steel. The longitudinal cracking occurred as a response to the stress resulting from these differences in heat flux. ${ }^{2)}$

\subsection{Mold Powder for High Speed Slab CC}

In order to prevent longitudinal cracking, it is customary to use a mold powder with a high solidification temperature where crystallization of cuspidine $\left(\mathrm{Ca}_{4} \mathrm{~F}_{2}-\right.$ $\left.\mathrm{Si}_{2} \mathrm{O}_{7}\right)$ has occurred. These physical properties can be achieved by increasing the $\mathrm{CaO} / \mathrm{SiO}_{2}$ ratio. The relation between solidification temperature and $\mathrm{CaO} / \mathrm{SiO}_{2}$ ratio is shown in Fig. 3. The relation between peak height of $\mathrm{X}$-ray diffraction for cuspidine $\left(\mathrm{Ca}_{4} \mathrm{~F}_{2} \mathrm{Si}_{2} \mathrm{O}_{7}\right)$ and the $\mathrm{CaO} / \mathrm{SiO}_{2}$ ratio is shown in Fig. 4. For mild cooling, a $\mathrm{CaO} / \mathrm{SiO}_{2}$ ratio is $1.1-1.3$ is adequate.

For a high speed casting, powder consumption is an important parameter. In order to achieve such high powder consumption, low viscosity and a high melting rate are necessary. Low viscosity and high solidification temperature were obtained by 1) increasing the $\mathrm{CaO} /$ $\mathrm{SiO}_{2}$ ratio, 2) increasing the contents of $\mathrm{Na}_{2} \mathrm{O}$ and $\mathrm{F}$. A high melting rate was obtained by (i) decreasing the bulk density, (ii) decreasing the carbon content and (iii) increasing the carbonate content. ${ }^{9)}$ The relation between carbonate content and melting rate is shown in Fig. 5.

The specifications of a satisfactory mold powder for high speed casting are shown in Table 1. Mold powders for both low carbon and hypo-peritectic steel have high $\mathrm{CaO} / \mathrm{SiO}_{2}$ ratio and a high solidification temperature. Mold powders for low carbon steel with a higher speed range should have lower viscosities and solidification temperatures.

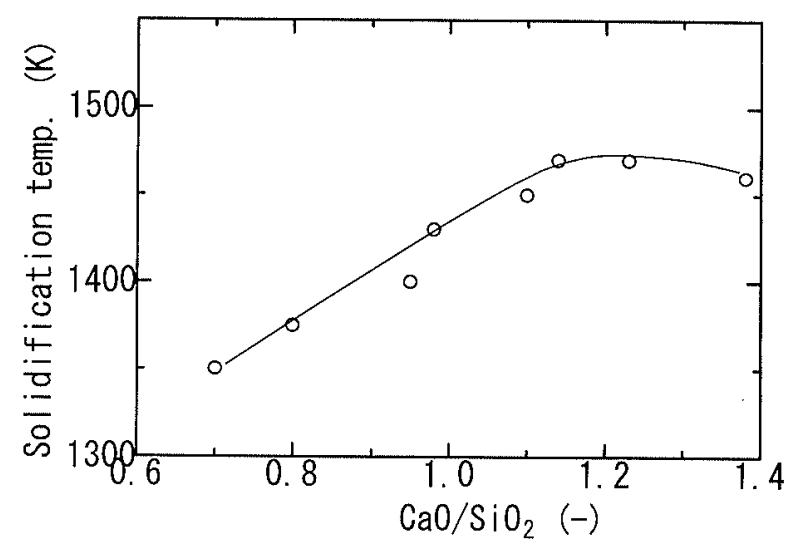

Fig. 3. Solidification temperature as a function of $\mathrm{CaO} / \mathrm{SiO}_{2}$. $\left(\mathrm{Al}_{2} \mathrm{O}_{3}: 6.3, \mathrm{Na}_{2} \mathrm{O}: 0.8, \mathrm{~F}: 8\right.$ (mass\%))

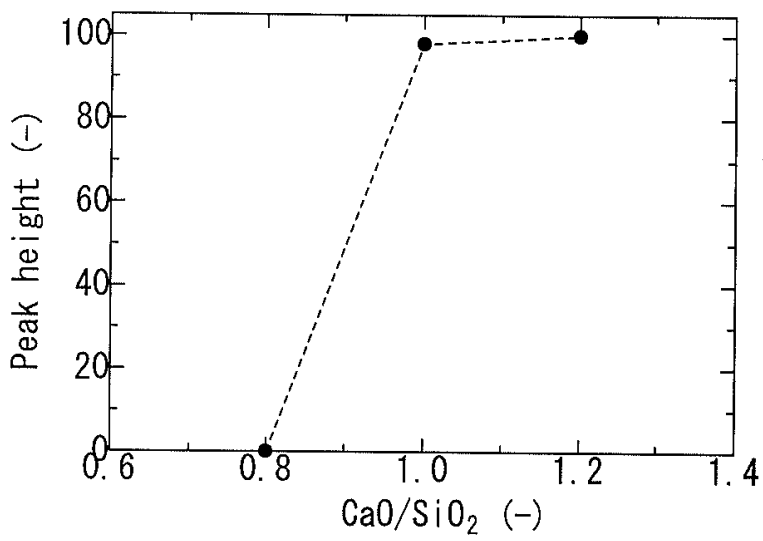

Fig. 4. Peak height of cuspidine as a function of $\mathrm{CaO} / \mathrm{SiO}_{2}$. $\left(\mathrm{Al}_{2} \mathrm{O}_{3}: 4, \mathrm{MgO}: 8, \mathrm{Na}_{2} \mathrm{O}: 8, \mathrm{~F}: 8\right.$ (mass\%))

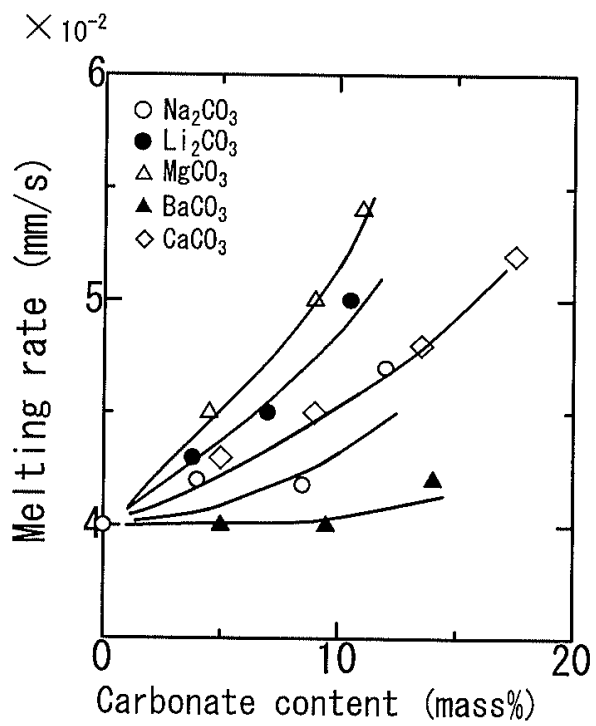

Fig. 5. Relation between melting rate and carbonate content. ${ }^{9)}$

Figure 2 shows the deference of heat flux distribution of the horizontal direction of the wide face using defferent powders. The heat flux decreases by using mild cooling mold powder. Figure 6 shows such differences in heat flux in the horizontal (transverse) direction as a function of the heat flux of the center of the wide face of the mold.

By using mild-cooling mold powder, it is possible to 
Table 1. Specifications of mold powder for high speed slab CC.

\begin{tabular}{lccc}
\hline & \multicolumn{2}{c}{ for low carbon } & for middle carbon \\
& A & B & C \\
\hline Casting speed $(\mathrm{m} / \mathrm{min})$ & 5.0 & $3.0-4.0$ & 3.0 \\
Viscosity $1573 \mathrm{~K}(\mathrm{~Pa} \cdot \mathrm{s})$ & 0.015 & 0.035 & 0.060 \\
Solidification temp. $(\mathrm{K})$ & 1243 & 1233 & 1507 \\
$\mathrm{Bulk} \mathrm{density}\left(\mathrm{kg} / \mathrm{m}^{2}\right)$ & 830 & 825 & 850 \\
$\mathrm{CaO} / \mathrm{SiO}_{2}(-)$ & 1.20 & 0.95 & 1.24 \\
$\mathrm{Na}_{2} \mathrm{CO}_{3}$ (mass\%) & 14.7 & 11.9 & 9.8 \\
$\mathrm{Li}_{2} \mathrm{CO}_{3}$ (mass\%) & 8.9 & 0 & 0 \\
Free carbon (mass\%) & 1.5 & 1.5 & 1.2 \\
\hline
\end{tabular}

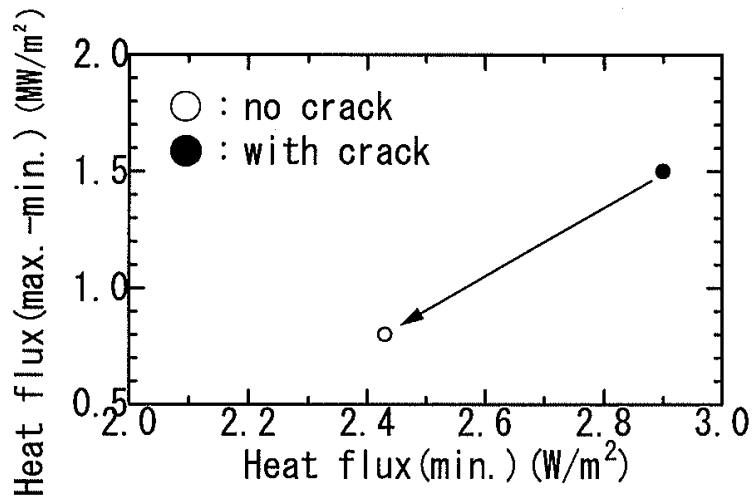

Fig. 6. Relation between heat flux (max. $-\min$ ) and heat flux (min.).

reduce both the absolute heat flux and the differences in heat flux of the horizontal direction. Longitudinal cracking decreases as a result of the mild-cooling.

\section{Mild Cooling Mold Powder for Round Billet CC}

For a round shape billet caster, the shape of the mold cross-section is a disadvantage. To make matters worse, high speed casting, with a speed range of $3.0 \mathrm{~m} / \mathrm{min}$, is necessary to ensure a high level of productivity.

For a round-shaped billet caster, it is necessary that the mold wall and solidified shell maintain close contact with the powder film in order to ensure there is no bulging in the solidified shell. It is therefore, impossible to use the same high $\mathrm{CaO} / \mathrm{SiO}_{2}$ ratio in the mold powder used in the slab casting, since the heat flux in the mold is chaotic. Consequently, it is necessary to develop a new mold powder, capable of providing both mild cooling and uniform heat transfer. Therefore, a mold powder with low $\mathrm{CaO} / \mathrm{SiO}_{2}$ ratio, high magnesia content and high solidification temperature has been developed to meet these requirements.

Test casting was carried out in order to determine the effects of the $\mathrm{CaO} / \mathrm{SiO}_{2}$ ratio and solidification temperature of mold powder had on round billet casting. The specifications of the mold powder used for test casting are shown in Table 2 . The relation between $\mathrm{CaO} / \mathrm{SiO}_{2}$ and the solidification temperature is shown Fig. 7.

Three castings were carried out using the mold powder in current use denote proper and two test powders 1 and 2. The relations between the heat flux calculated from the water temperature of the mold and the casting speed
Table 2. Specifications of mold powder for round CC.

\begin{tabular}{|c|c|c|c|c|c|c|}
\hline & \multirow{2}{*}{$\begin{array}{c}\mathrm{CaO} / \mathrm{SiO}_{2} \\
(-)\end{array}$} & \multirow{2}{*}{$\begin{array}{l}\text { Solid. temp. } \\
\qquad(\mathrm{K})\end{array}$} & \multicolumn{4}{|c|}{ Chemical compositions (mass $\%$} \\
\hline & & & $\mathrm{MgO}$ & $\mathrm{Al}_{2} \mathrm{O}_{3}$ & $\mathrm{Na}_{2} \mathrm{O}$ & $\mathrm{ZrO}_{2}$ \\
\hline Proper & 0.85 & 1348 & 3.9 & 6.9 & 3.8 & 0 \\
\hline Test 1 & 0.87 & 1418 & 1.7 & 6.9 & 4.8 & 0 \\
\hline Test 2 & 1.00 & 1358 & 2.0 & 6.8 & 7.8 & 0 \\
\hline Test 3 & 1.25 & 1453 & 2.0 & 6.9 & 4.0 & 3.4 \\
\hline Improved & 0.85 & 1473 & 8.0 & 4.6 & 1.5 & 0 \\
\hline
\end{tabular}

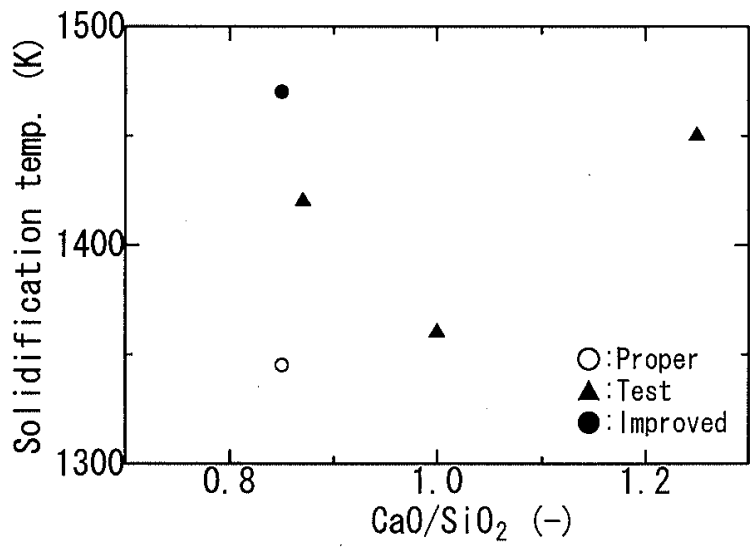

Fig. 7. Relations between solidification temperature and $\mathrm{CaO} / \mathrm{SiO}_{2}$ ratio for test powder.

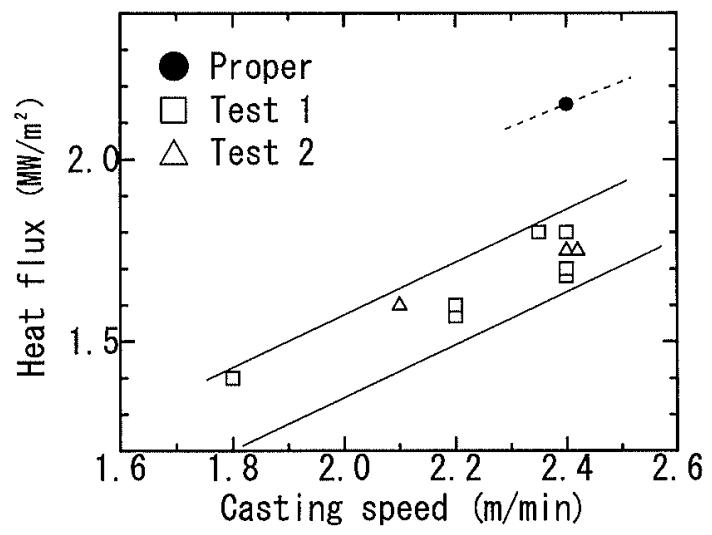

Fig. 8. Relation between heat flux and casting speed.

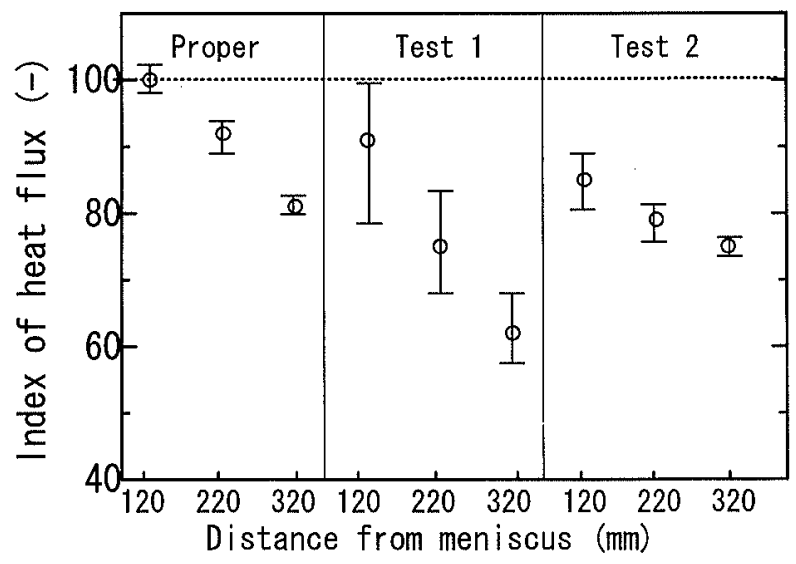

Fig. 9. Relation between heat flux and distance from meniscus.

is shown in Fig. 8. It can be seen the heat fluxes recorded with test powders 1 and 2 were lower. The heat fluxes calculated from the mold temperatures are shown in Fig. 9. The heat flux is the highest when using the proper 


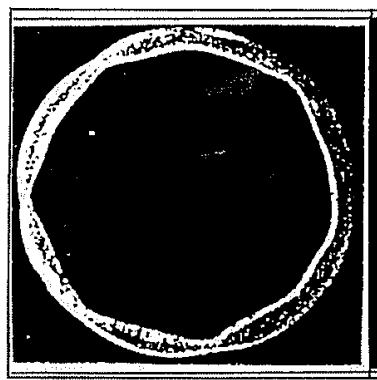

Proper

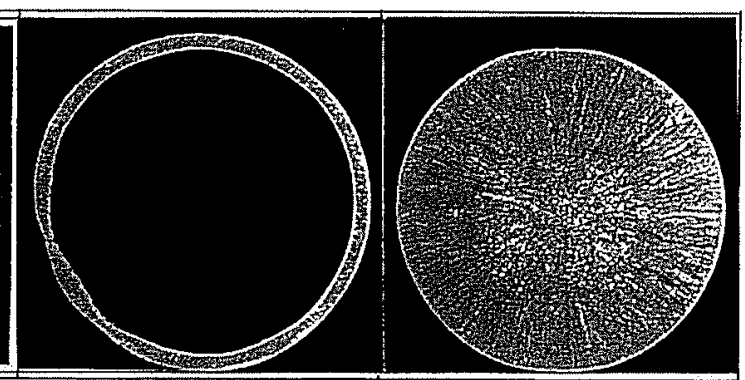

Test 3
Improved

Fig. 10. Macro structures of cross section of round billet.

powder in current use with a low $\mathrm{CaO} / \mathrm{SiO}_{2}$ ratio and low solidification temperature. The heat flux decreased when test powders 1 and 2 were used. However, the heat flux recorded in lower part of the mold when using test powder 1 was both low and inconsistent. This results from the fact that the contact between mold wall and solidined shell is not uniform. This problem is characteristic of round shaped casting. For uniform solidification during the initial stage, mild cooling is necessary, and both test powders 1 and 2 were sufficient for this purpose.

The casting results obtained with the proper powder in current use, test powder 3 and an improved powder for industrial use are described below. The proper powder is a normal type billet powder with a low $\mathrm{CaO} /$ $\mathrm{SiO}_{2}$ ratio; test powder 3 has the same principles as normal slab mild cooling powder. In contrast, the improved powder has a low $\mathrm{CaO} / \mathrm{SiO}_{2}$ ratio, high solidification temperature and promotes crystalization through the addition of MgO. Macro structures of billet cross sections obtained when three different powders are shown in Fig. 10. In the case of the proper powder, breakout occured at $2 \mathrm{~m} / \mathrm{min}$. The cross section of the breakout shell showed a periodically uneven solidified shell thickness. In the case of test powder 3, the solidified shell thickness is even. This shows that the effect of mild cooling was sufficient. However, breakout occurred as a result of a small depression resulting from uneven solidification during the initial stage of $2 \mathrm{~m} / \mathrm{min}$. In the case of the improved powder, a casting speed of $3.0 \mathrm{~m} /$ min was achieved without breakout and the shape of cross section was good. Figure 11 shows fluctuation of mold temperature. In the case of using test powder 3 with high basicity, mold temperature is not stabilized. Because the high basicity powder does not packed closely between solidified shell and mold wall for round billet. The powder film of low basicity has much glassy part, and this glassy film contact with mold wall closely. The character of mild cooling is ensured by high $\mathrm{MgO}$ content. The crystal observed in powder film with low basicity and high $\mathrm{MgO}$ content is confirmed as $\mathrm{MgSiO}_{3}$ by $\mathrm{X}$-ray analysis.

The wide range casting speeds used in successful casting trials with the improved powder are shown in Fig. 12 as a function of carbon content of steel. This shows the great benefits which can be obtained by the introduction

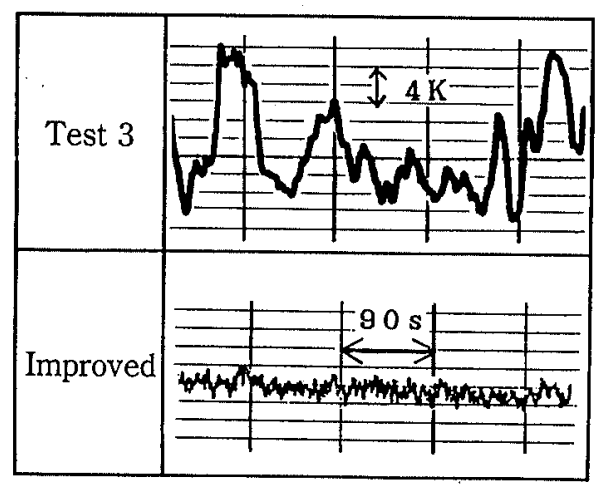

Fig. 11. Fluctuation of mold temperature for the round billet caster.

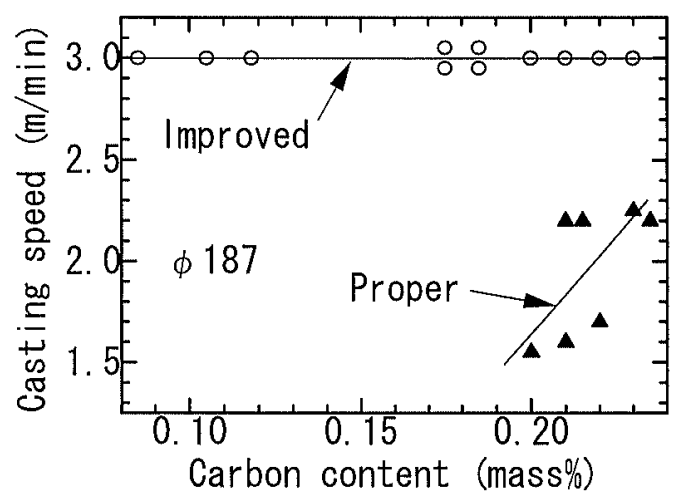

Fig. 12. Casting speed of round billet caster.

of the new mild cooling mold powder.

\section{Heat Transfer between Mold and Solidified Shell}

Thermal transfer between the solidified shell and the mold wall contains contributions from both radiation and lattice conductivity. In this study, the effect of radiation conduction was determined from the data obtained for the heat transfer in a laboratory scale experiment ${ }^{10,11)}$ and the thermal conductivity was measured using the hot wire method. ${ }^{12)}$ Figure 13 shows experimental apparatus for measuring total heat resistance between the mold wall and the solidified shell. The relation between total heat resistance and powder film thickness is shown Fig. 14. A value of $1.2 \mathrm{~W} / \mathrm{mK}$ was obtained for the effective thermal conductivity of the powder film $\left(k_{\text {eff }}\right)$ from the reciprocal of the slope 


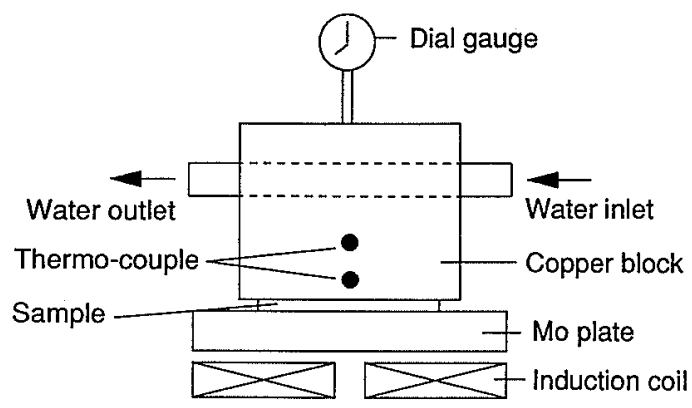

Fig. 13. Apparatus for measuring total heat resistance between the mold wall and solidified shell.

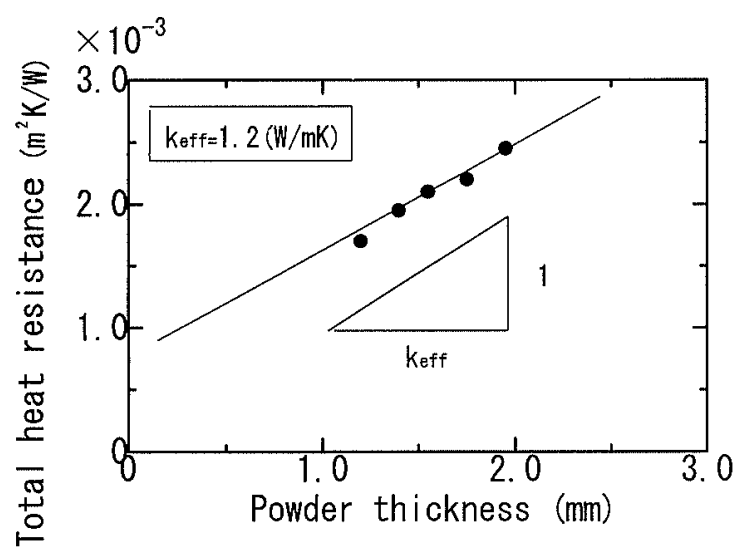

Fig. 14. Relation between powder film thickness and total heat resistance.

$\left(\mathrm{Al}_{2} \mathrm{O}_{3}: 3.7, \mathrm{MgO}: 8.6, \mathrm{Na}_{2} \mathrm{O}: 8.2, \mathrm{~F}: 7.7\right.$ (mass\%), $\left.\mathrm{CaO} / \mathrm{SiO}_{2}: 1.1(-)\right)$

(temp. of Mo plate $1523 \mathrm{~K}$, film thickness $1 \mathrm{~mm}$ )

(Fig. 14). The thermal conductivity of the mold powder measured using the hot wire method is shown in Fig. 15. From the results shown in Figs. 14 and 15, the radiation conduction contribution to the thermal transfer in powder film was derived. Thermal conductivities of solid powder film and liquid powder film $\left(k_{\mathrm{S}}, k_{\mathrm{L}}\right)$ were determined 1.0 and $1.4 \mathrm{~W} / \mathrm{mK}$.

$$
\begin{aligned}
Q_{\mathrm{t}} & =\frac{T_{\mathrm{s}}-T_{\mathrm{m}}}{d} \times k_{\text {eff }}=\frac{T_{\mathrm{s}}-T_{\mathrm{p}}}{d_{\mathrm{L}}} \times k_{\mathrm{L}}+q_{\mathrm{L}} \\
& =\frac{T_{\mathrm{p}}-T_{\mathrm{m}}}{d_{\mathrm{S}}} \times k_{\mathrm{S}}+q_{\mathrm{s}} \ldots \ldots \ldots \ldots \ldots \ldots \ldots \ldots \ldots \ldots \ldots \ldots \ldots \ldots \ldots
\end{aligned}
$$

Where $Q_{\mathrm{t}}$ is total heat flux $\left(6.4 \times 10^{5} \mathrm{~W} / \mathrm{m}^{2}\right), T_{\mathrm{s}}$ is surface temperature of Mo plate $(1473 \mathrm{~K}), T_{\mathrm{m}}$ is powder film surface temperature of the cooling block side, $T_{\mathrm{p}}$ is the solidification temperature of the mold powder $(1373 \mathrm{~K}), d$ is the total thickness of the powder film $(1.2 \mathrm{~mm}), d_{\mathrm{L}}$ is the thickness of the liquid powder film, $d_{\mathrm{S}}$ is the thickness of the solid powder film, $q_{\mathrm{L}}$ is a heat flux of radiation in the liquid powder film, $q_{\mathrm{s}}$ is the heat flux of radiation in the solid powder film. Values of $1.7 \times 10^{5}$ and $0.4 \times 10^{5} \mathrm{~W} / \mathrm{m}^{2}$ were obtained respectively for $q_{\mathrm{L}}$ and $q_{\mathrm{S}}$ using $d_{\mathrm{L}}=0.3 \mathrm{~mm}$ which was determined by microscopic analysis of the film. Radiation contributions were determined to contribute $27 \%$ of the total heat transfer in liquid powder film and $6 \%$ in solid film.

Table 3 shows the thermal transfer data obtained in present work. Radiation contributions of solid powder film is lower than liquid powder film. Therefore, the

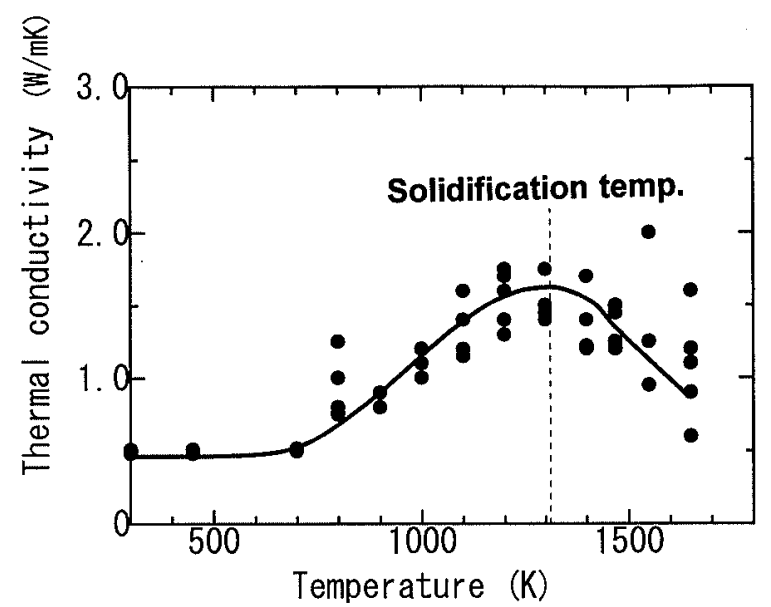

Fig. 15. Thermal conductivity of mold powder.

$\left(\mathrm{Al}_{2} \mathrm{O}_{3}: 3.7, \mathrm{MgO}: 8.6, \mathrm{Na}_{2} \mathrm{O}: 8.2, \mathrm{~F}: 7.7\right.$ (mass \%), $\left.\mathrm{CaO} / \mathrm{SiO}_{2}: 1.1(-)\right)$

(hot wire method, platinum wire $20 \mathrm{~mm}$ long $\times 0.6$ $\mathrm{mm} \phi, 2.0 \mathrm{~A}$ )

Table 3. Thermal transfer data of powder film.

\begin{tabular}{lcccc}
\hline & \multicolumn{2}{c}{ Heat flux $\left(\times 10^{5} \mathrm{~W} / \mathrm{m}^{2}\right)$} & Temperature gradient \\
\cline { 2 - 3 } & $Q_{1}$ & Radiation & Conduction & $\left(\times 10^{5} \mathrm{~K} / \mathrm{m}\right)$ \\
\hline Liquid film & 6.4 & 1.7 & 4.7 & 3.33 \\
Solid film & 0.4 & 6.0 & 6.00 \\
\hline
\end{tabular}

temperature gradient of solid powder film is bigger than solid powder film. These data means high solidification temperature is effectively for mild cooling.

\section{Conclusion}

In this study, we have discussed principle factors involved with the development of the mild cooling mold powders used to reduce heat transfer in the continuous casting of various steel grade. The results can be summarized as follows;

(1) A high $\mathrm{CaO} / \mathrm{SiO}_{2}$ ratio mold powder with a high solidification temperature is the most suitable for slab casting.

(2) A low $\mathrm{CaO} / \mathrm{SiO}_{2}$ ratio mold powder with a high solidification temperature is the most suitable for roundbillet casting.

(3) The effect of radiation in liquid powder film is bigger than solid powder film.

\section{REFERENCES}

1) Y. Sugitani and M. Nakamura: Tetsu-to-Hagané, 65 (1979), 1702.

2) S. Hiraki, T. Kanazawa, K. Nakajima, T. Murakami, K. Nakai and Y. Shirai: CAMP-ISIJ, 4 (1991), 1284.

3) S. Umeda, Y. Tsukaguchi, H. Miki, Y. Hitomi and M. Kawamoto: CAMP-ISIJ, 7 (1994), 302.

4) Y. Sugitani, M. Nakamura and T. Watanabe: Tetsu-to-Hagané, 67 (1981), 1508.

5) K. Nakai, T. Sakashita, M. Hashio, M. Kawasaki, K. Nakajima and Y. Sugitani: Tetsu-to-Hagané, 73 (1987), 498.

6) H. Murakami, M. Suzuki, T. Kitagawa and S. Miyahara: Tetsu-to-Hagané, 78 (1992), 105.

7) K. Nakajima, M. Kawamoto, T. Kanazawa, K. Nakai, K. Marukawa and T. Tanaka: CAMP-ISIJ, 4 (1991), 1247. 
ISIJ International, Vol. 37 (1997), No. 2

8) K. Ichikawa, A. Morita and Y. Kawabe: Shinagawa Tech. Rep., 36 (1993), 99.

9) M. Kawamoto, K. Nakajima, T. Kanazawa and K. Nakai: $I S I J$ Int., 34 (1994), 593.

10) S. Ohmiya, K. H. Tacke and K. Schwerdtfeger: Ironmaking
Steelmaking, 10 (1983), 24.

11) A. Yamauchi, K. Sorimachi, T. Sakuraya and T. Fujii: ISIJ Int., 33 (1993), 140.

12) K. Nagata, M. Susa and K. Goto: Tetsu-to-Hagané, 69 (1983), 1418. 